\title{
EPIDEMIOLOGY AND MICROORGANISM PROFILE OF PYONEPHROSIS
}

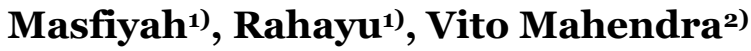 \\ 1)Department of Microbiology, Faculty of Medicine, Universitas Islam Sultan Agung \\ Semarang, Central Java \\ 2)Department of Surgery, Faculty of Medicine, Universitas Islam Sultan Agung \\ Semarang, Central Java
}

\begin{abstract}
Background: Pyonephrosis is an infection of the kidneys' collecting system. Pus collects in the renal pelvis and causes distension of the kidney. It can cause kidney failure. This study aimed to describe the epidemiology and microorganism profile of pyonephrosis.

Subjects and Method: This was a cross sectional study carried out at Sultan Agung Islamic Teaching Hospital, Semarang, Central Java. A sample of 42 inpatients with pyonephrosis was selected for this study. The dependent variable was microorganism profile. The independent variables were age and gender. Epidemiological data were taken from the medical record. Microorganism profile and sensitivity were analyzed from pus collected from surgery. Culture was performed using Blood Agar Plate and Mac Conkey technique. Sensitivity to antibiotic was tested by CLSI diffusion method. Microorganism profile was described in percent.

Results: Of all 42 patients with pyonephrosis, 38 (90.5\%) patients aged 26 to 64 years and $23(54,76 \%)$ patients were male. Of all types of gram-negative microorganism, 12 (28.57\%) were Escherichia coli, 5 (11.90\%) Klebsiella pneumonia, 3 (7.1\%) Pseudomonas aeruginosa, and 1 (2.3\%) non typhoidal Salmonella. Of all types of gram-positive microorganism, 2 (4.7\%) were Staphylococcus aureus and 1 (2.3\%) Streptococcus viridans. Only 2 (4.7\%) were anaerobic bacteria. Some samples were sterile. As many as 2 (16\%) were Escherichia coli that produces extended spectrum beta lactamase (ESBL), which is an isolate resistant to the third generation Cephalosporin. All (100\%) Staphylococcus aureus were methicillin sensitive.

Conclusion: Most patients with pyonephrosis were adults. Percents of male and female patients were comparable. Gram-negative microorganisms outweigh gram-positive microorganism.
\end{abstract}

Keywords: pyonephrosis, epidemiology, microorganism profile.

\section{Correspondence:}

Masfiyah. Department of Microbiology, Faculty of Medicine, Universitas Sultan Agung, Semarang, Central Java. Email: Masfiyah@unissula.ac.id.

Mobile: 081901187887.

The 4th International Conference on Public Health Best Western Premier Hotel, Solo, Indonesia, August 29-30, 2018 | 118 https://doi.org/10.26911/theicph.2018.01.79 